Research Article

\title{
Dynamic Evolution of the Zinc-Nickel Battery Industry and Evidence from China
}

\author{
Xiangze Shi, ${ }^{1}$ Xiao Li $\mathbb{D},{ }^{2}$ Zijian He, ${ }^{3}$ and Hui Jiang $\mathbb{D}^{3}$ \\ ${ }^{1}$ Grand Canyon University, Phoenix, AZ 85017, USA \\ ${ }^{2}$ Zhejiang University of Water Resources and Electric Power, Zhejiang, Hangzhou 310018, China \\ ${ }^{3}$ College of Management and Economics, Tianjin University, Tianjin 300072, China \\ Correspondence should be addressed to Xiao Li; xiaoli20180828@126.com and Hui Jiang; huijiang369@163.com
}

Received 29 May 2021; Revised 30 June 2021; Accepted 14 July 2021; Published 9 August 2021

Academic Editor: A. E. Matouk

Copyright ( $\odot 2021$ Xiangze Shi et al. This is an open access article distributed under the Creative Commons Attribution License, which permits unrestricted use, distribution, and reproduction in any medium, provided the original work is properly cited.

This paper analyzes the development prospects of zinc-nickel battery industry, further investigates the industry competition in existing markets by mathematical modeling, calculates the equilibrium price and profit of the oligarch competition by using the method of Stackelberg equilibrium and Nash equilibrium, and makes a comparison between them. Then, we study and model the case of renting and selling simultaneously. In addition, we also study the impact of futures prices on the zinc-nickel battery companies and carry out numerical simulation. At the end of this paper, we analyze the location of zinc-nickel battery enterprises and the industry development under the COVID-19 pandemic. The finding show that the reduction of raw material cost is of great help to the development of the zinc-nickel battery industry.

\section{Introduction}

It has been around 200 years since the battery was firstly invented. In 1780, Alessandro Volta dipped zinc and tin plates into salt water and found an electric current flowing through the wire connecting the two plates. It was the first battery in human history and also the first time zinc was used in a battery. In 1859, Gaston Plante invented rechargeable lead-acid battery, and rechargeable iron-nickel battery was invented by Thomas Edison in 1890. Since then, nickel has been widely used in the positive electrode of batteries. Since the twentieth century, both the battery theory and technology got into a period of stagnation. But after World War II, battery technology began to develop rapidly. Alkaline zinc-manganese dioxide batteries meet the needs of heavyload applications. Harris proposed the use of organic electrolyte as electrolyte for lithium batteries in 1958, and this technology has been available for military and civilian use since the early 1970s. Subsequently, due to environmental considerations, the research of the battery industry began to turn to the storage battery.
The first battery factory of China was founded in Shanghai in 1911. In 1921, Shanghai storage battery factory was established, which was the first professional lead storage battery factory in China. In 1941, the telecommunications material factory affiliated to the Third Bureau of the Central Military Commission of Yan'an began to produce zincmanganese dry batteries and repair lead-acid batteries. After the founding of the People's Republic of China, domestic battery industry developed rapidly. In 1957, the establishment of the Chemical Power Research Office of the Electrical Materials Bureau of the Ministry of Mechanical and Electrical Engineering was established under the instruction of central government, which became China's first professional research institute, namely, the former Chemical Power Research Institute of the Ministry of Electronic Industry (Tianjin Power Research Institute). At present, China's battery industry has been developed by leaps and bounds, forming a complete industrial chain, and the technology is also at a leading level in the world.

For the current battery industry in China, the main problems are serious environmental pollution and waste of 
resources. The low degree of automation and mechanization directly results in great pollution in the production process as well as irreversible harm to the workers. The dry battery industry has been nicknamed "pollution enterprises" or "black industry" for a long time. These pollutants mainly include $\mathrm{MnO}_{2}$ powder, $\mathrm{HgO}$, asphalt smoke, smoke, and paraffin smoke. Mercury is the most concerned chemical element, as a highly toxic heavy metal; even a trace of Mercury is seriously toxic to human. The production and import of mercury batteries has been banned in developed countries since 1994 . However, most manufacturers in China still produce mercury batteries. The main pollutants of lead-acid battery industry are $\mathrm{Pb}$, Pbo dust, acid fog, and waste acid. Lead is also a heavy metal with high toxicity. Chronic lead poisoning is mainly manifested in nervous system damage, renal dysfunction, and anemia. Most of the raw materials of $\mathrm{Cd}-\mathrm{Ni}$ batteries are powders, which lead to dust pollution. And the toxicity of $\mathrm{Cd}$ is even greater; it can accumulate in the kidney and bone and cause renal dysfunction. In addition, calcium in the bones is replaced by cadmium, making the bones soft and painful. Alkali mist and waste acid are also important pollutants. Verdigris and pulp phenomenon is quite common for zincmanganese dry batteries, while alkali spray or burst may occur in the use of $\mathrm{MH}-\mathrm{Ni}$ batteries. To reduce the emissions of harmful pollutants, protect the environment, maintain the ecological balance, and protect the limited resources on the Earth, it is necessary to expand the types of resources as far as possible, use the resources with abundant reserves, and utilize the resources that are conducive to environmental protection.

As a substitute of lead-acid battery, zinc-nickel battery has the characteristics of large capacity, high specific capacity and good safety, which will be the key industry to be developed in China in the future. The anode and cathode of the zinc-nickel battery are made of nickel and zinc, respectively, so the high capacity of the zinc-silver electrode and the long life of the Ni-Cr battery are both provided. Its specific capacity can reach $50-80 \mathrm{Wh} / \mathrm{kg}$, specific power more than $200 \mathrm{~W} / \mathrm{kg}$, can work in minus 20 degrees Celsius to zero 60 degrees Celsius, the use of space. Its raw material cost is low, pollution is small, and it is a kind of green environmental protection chemical battery.

Zinc-nickel batteries are mainly used for electric bicycles, electric sightseeing vehicles, and other vehicles. With the implementation of the "new national standard" for electric bicycles, the electric bicycle industry is gradually standardized. Traditional lead-acid electric vehicles need to be withdrawn from the market gradually, and the market demand for zinc-nickel batteries will increase further. In addition, with the gradual opening of the market of shared electric bikes, there is a large amount of demand space, which is a great news for the zinc-nickel battery industry.

As a company mainly producing zinc-nickel batteries, ZincPower is of great development space in the future. To make some meaningful suggestion to the development of the enterprise, this paper mainly analyzes the zinc-nickel battery industry. The research is divided into three parts. The first part is the market research of zinc-nickel battery, the second part is the cost research of zinc-nickel battery, and the third part is the development research of ZincPower.

\section{Research Reviews}

2.1. Research on Supply Chain Game. Korpeoglu et al. [1] studied supply chains in which multiple suppliers sell to multiple retailers in a wholesale market. They found that integration may reduce the total profit of companies in a retailer-oriented supply chain. Feng et al. [2] investigated a dynamic game where a seller and a buyer bargain over the quantity and price of products. Beer et al. [3] discussed a supply chain with a buyer and upstream suppliers. They showed that investments can be seen as a signal of trustworthiness. Shang et al. [4] studied the information sharing problem in supply chain. The results showed that the retailer would like to sell information sequentially instead of concurrently to the manufacturers. Hafezalkotob et al. [5] investigated the regulator's policies on environmental protection in regular supply chains and illustrated how the budgetary constraints impact the efficiency by numerical experiment. Ang et al. [6] investigated a three-level supply chain and found that the manufacturer usually prefers less overlap. Gao et al. [7] considered the supply chain coordination problem of random demand in the infinite period and proposed a delayed payment contract to coordinate the supply chain to achieve Pareto optimization. Giri and Maiti [8] established a supply chain model.

2.2. Research on the Supply Chain Operations. In the study of Mallidis et al. [9], companies believe that carbon tax should be considered in the decision-making process as a cost, and the decision variable will have the characteristic of uncertainty. Benjaafar et al. [10] considered the carbon emission limitation and the trading mechanism as an influencing factor in the process of corporate decision-making. Paksoy et al. [11] weighed carbon emissions with corporate revenue and social utility and made joint decisions.

Supply chain contracting is an important subject in production research, management science, and operation management. Many previous studies have studied how supply chain contracts and information updates affect each other, and how supply chain contracts can optimize the efficiency of individual members by reducing information asymmetry. Incentive contracts can promote information sharing between supply chain members and overcome the problem of double marginal effect: double marginal effect means that in a supply chain, members have different marginal standards while ignoring the other, which leads to the difference between decentralized decision-making and centralized decision-making, such as order volume [12]. The principal-agent problem in economics has led the research direction of supply chain contracts, in which at least two supply chain members (such as the buyer and the seller) participate in the transaction [13]. Supply chain contracting is now significantly affecting supply chain operations management and production research [14]. In the news provider type model, the supply chain contract has been identified as an incentive adjustment scheme, because it helps to make decentralized decision-making the same (or at least close) to centralized decision-making, 
thereby helping the supply chain to improve efficiency. Information asymmetry will negatively affect the efficiency of the supply chain, but appropriate measures can reduce or eliminate the effects [15]. For example, when dealing with information asymmetry, the contract can provide buyers with more choices and flexibility. Supply chain contracts include wholesale price contracts, revenue sharing contracts, return contracts, two-part tariff contracts, service commitment contracts, and quantity flexibility [16].

Hafezalkotob [17] consider the chain and a formal supply chain competition under the government's financial intervention. Each supply chain has a manufacturer and a retailer, and the two retailers compete for retail prices in a highly competitive market. The results of the article show that the government's fiscal intervention has a significant impact on the profits of supply chain members. Research by Tian et al. [18] analyzed the influence of behavioral factors and communication channels on supply chain management and combined them with evolutionary game theory to establish a system dynamics model. Based on the Chinese automobile industry, the study found that the government and consumers have different influences on the diffusion process of supply chain management. Factory subsidies are better than consumers' promotion of the proliferation of green supply chain management, and environmental awareness is another influential key factor. Through its application in China's automobile industry, this model can be applied to manufacturing countries like China. Zhang et al. [19] considered the cooperative game and noncooperative game in the mixed production mode of the supply chain and concluded from the result of the game equilibrium that under different production modes, the system performance in the cooperative game is always better than that in the noncooperative game. Sarker et al. [20] established an optimal ordering decision model for deteriorating items under the conditions of inflation, allowable deferred payment, and allowable shortage and gave the optimal order quantity and maximum allowable shortage. Chern et al. [21] constructed a supply chain model for both the supply and demand sides based on the consideration that delayed decision-making has a positive impact on demand and a negative effect on costs and obtained the optimal solution for both sides under the noncooperative Nash equilibrium.

2.3. Research on the Dynamic System. The performance of evolutionary games in nonlinear dynamic systems in supply chain management is extremely prone to complex dynamics such as chaos. The existing literature summarizes and elaborates on the complex behaviors in the supply chain in detail. Waltman et al. [22] studied the evolution model of price competition among spatially distributed enterprises. Based on the theory of bounded rationality, Yassen and Elsadany [23] studied a Cournot duopoly game and found that if one of the companies uses delayed bounded rationality, it will be easier to reach the Nash equilibrium. Based on a two-stage delay game model, Ma and Si [24] analyzed the stability of the system related to delay and weight. The article also uses state variable feedback and parameter change methods to control the chaotic state of the system. Elsadany et al. [25] established a dynamic game system with four different companies and believed that the application of delayed feedback control methods can control the chaos of the system. Shi et al. [26] also established a dynamic duopoly game model and showed images of bifurcation and chaos in the system. Tramontana and Elsadany [27] used random demand theory to establish and analyze a three-oligarch model. The analysis results show that the dynamic characteristics of the system accompanied by the stochastic equation may be periodic, quasiperiodic, or chaotic. $\mathrm{Li}$ and $\mathrm{Ma}$ [28] studied the price decisions of dualchannel retailers between online channel and traditional channel and used the bifurcation theory of dynamic systems to analyze the impact of delayed decision-making on the stability and complexity of the entire system. Xie et al. [29] analyzed the optimal subsidy strategy offered to a vaccine supply chain. The results show that for a higher innovation effort, the production-based subsidy rate is better off if there is a low innovation cost coefficient. Lou and $\mathrm{Ma}$ [30] investigated the complexity of sales effort and carbon emission reduction effort in a Bertrand household appliance supply chain. The finding implies that the adjustments of price will affect the supply chain stability and profits. Xie et al. [31] considered a supply chain involving two manufacturers and made some managerial suggestions to the manufacturers for keeping the system stable. Puu [32] summarized the chaotic duopoly. The self-control feedback continuous control of chaos is studied. Zhang and Yu [33] established Hotelling's model of bounded rationality to analyze the complexity of dynamic economic systems. Gao and Ma [34] studied the complex dynamic behavior of the financial system. In addition to macroscopic perspective, there are also microscopic dynamic studies. Ma and Ren [35] thoroughly demonstrated the Hopf bifurcation condition in the fractional-order system model by combining the ISLM model and the fractional-order calculus theory. Ma and Xie [36] considered the profits and stability through the supply chain system under policy intervention. Most of the existing literature studies focus on the short-, medium-, and long-term game strategies of the supply chain [37-39]. Some studies also analyze the dynamic characteristics of the dynamic game model of the dual channel supply chain system in the long-term game [40-42], such as bifurcation, initial value sensitivity, and irreversible endomorphism. Market turbulence and instability will not only affect the stability of the economic system but also affect the long-term profits and game strategies of different enterprises $[40,43,44] . \mathrm{Xu}$ and $\mathrm{Ma}$ [45] studied a nonlinear dynamic system composed of solar photovoltaic supply chain to study the impact of long-term operation strategy, equilibrium stability, and conservative and radical strategies on the system. Bao and Ma [46] studied the short-term and long-term repeated game behavior of two parallel supply chains producing electric vehicles and fuel vehicles. After considering three game models (noncooperation, cooperation, and cost sharing contract), the dynamic behavior of two parallel supply chains in long-term repeated game is analyzed. Zhang and Sarvary [47] studied the complex dynamic behavior of the differentiation with user-generated system, and the research results have good theoretical value. 


\section{Market Research of the Zinc-Nickel Battery}

At present, there are many enterprises producing zinc-nickel batteries in China, while two to three enterprises are of large scale and high output, namely, CHILWEE Power Supply Co., Ltd., ZincPower (Tianjin) New Energy Co., Ltd., and Chaoli (Henan) New Energy Co., Ltd. Taken these into consideration, the domestic zinc-nickel battery market is an oligopoly market. In the following chapters, we will carry out supply chain modeling and simulation of this market, so as to analyze and study the sales situation of zinc-nickel battery.

\subsection{Oligopoly Game Analysis with Uncertain Market Demand}

3.1.1. Game Analysis of Duopoly. At present, there are many enterprises producing zinc-nickel battery, but CHILWEE and ZincPower take the most market share, which means that the domestic zinc-nickel battery market is an oligopoly market, and the competition between the two companies is a Stackelberg game. As shown in Figure 1, CHILWEE plays the role as the pricing leader in the game, while ZincPower is the pricing follower.

The unit price of zinc-nickel batteries of CHILWEE is expressed as $p_{1}$, the production cost is written as $c_{1}$, the unit price of ZincPower is $p_{2}$, while the production cost is expressed in terms of $c_{2}$ The market demand of zinc-nickel batteries of CHILWEE is $D_{1}$, the market demand of ZincPower is $D_{2}, A$ represents the total demand of the market, and $b$ and $d$ are the market competition coefficients of the two enterprises. $\varepsilon_{1}$ and $\varepsilon_{2}$ are the disturbance factors of demand of the two enterprises. And their values are shown as follows:

$$
\begin{aligned}
& D_{1}=A-p_{1}+b p_{2}+\varepsilon_{1}, \\
& D_{2}=A-p_{2}+b p_{1}+\varepsilon_{2} .
\end{aligned}
$$

Combining equations (1) and (2), the profits of the two enterprises are expressed as follows:

$$
\begin{aligned}
& \pi_{1}=\left(p_{1}-c_{1}\right)\left(A-p_{1}+b p_{2}+\varepsilon_{1}\right), \\
& \pi_{2}=\left(p_{2}-c_{2}\right)\left(A-p_{2}+b p_{1}+\varepsilon_{2}\right) .
\end{aligned}
$$

Since CHILWEE is the dominant player in the market, we first obtain the partial derivative of equation (4) $\partial \pi_{2} / \partial p_{2}$, and after obtaining the optimal price $p_{2}^{*}$, we substitute it into the partial derivative of equation (3) $\partial \pi_{1} / \partial p_{1}$ to obtain the optimal the optimal price $p_{1}^{*}$. From this, we can conclude that the optimal price and optimal profit of the two companies are, respectively,

$$
\begin{aligned}
& p_{1}^{*}=\frac{-2 a-a b-2 c_{1}+b^{2} c_{1}-b c_{2}-2 \varepsilon_{1}-b \varepsilon_{2}}{2\left(-2+b^{2}\right)} \\
& p_{2}^{*}=\frac{1}{2}\left(a+c_{2}+\epsilon_{2}+\frac{b\left(-2 a-a b-2 c_{1}+b^{2} c_{1}-b c_{2}-2 \epsilon_{1}-b \epsilon_{2}\right)}{2\left(-2+b^{2}\right)}\right) \\
& \pi_{1}^{*}=\frac{\left(2 a+a b+\left(-2+b^{2}\right) c_{1}+b c_{2}+2 \epsilon_{1}+b \epsilon_{2}\right)^{2}}{8\left(2-b^{2}\right)}, \\
& \pi_{2}^{*}=\frac{\left(-4 a-2 a b+a b^{2}+b\left(-2+b^{2}\right) c_{1}+\left(4-3 b^{2}\right) c_{2}-2 b \epsilon_{1}-4 \epsilon_{2}+b^{2} \epsilon_{2}\right)^{2}}{16\left(-2+b^{2}\right)^{2}} .
\end{aligned}
$$

With the development of enterprises, when the two enterprises have equal competitiveness, simultaneous pricing strategy will be adopted in the pricing process. In this case, the game between the two manufacturers is Nash game.
Here, we combine partial derivative equations $\partial \pi_{1} / \partial p_{1}$ and $\partial \pi_{2} / \partial p_{2}$ to get the optimal prices and profits of the two companies. The game results are as follows:

$p_{1}^{*}=p_{2}^{*}=-\frac{2 a+a b+2 c_{1}+b c_{2}+2 \epsilon_{1}+b \epsilon_{2}}{-4+b^{2}}$,
$\pi_{1}^{*}=\pi_{2}^{*}=\frac{1}{\left(-4+b^{2}\right)^{2}}\left(2 a+a b+\left(-2+b^{2}\right) c_{1}+b c_{2}+2 \epsilon_{1}+b \epsilon_{2}\right)\left(2 a+a b+2(-1+b) c_{1}+(-1+b) b c_{2}+2 \epsilon_{1}+2 b \epsilon_{1}-b^{2} \epsilon_{1}-b \epsilon_{2}+b^{2} \epsilon_{2}\right)$.

Since CHILWEE occupies a dominant position in the market, its production cost has an advantage, that is, $c_{1}<c_{2}$. Here, we assign the parameters as follows: $\left\{a, c_{1}, c_{2}, \epsilon_{1}, \epsilon_{2}\right\}=$ $\{10,1,1.2,1,1.2\}$ (Figure 2).
As shown in Figure 3, with the increase of $b$, the product price and profit of both enterprises will increase. This shows that if the substitutability of the two companies' products increases, the competition between the two companies will 


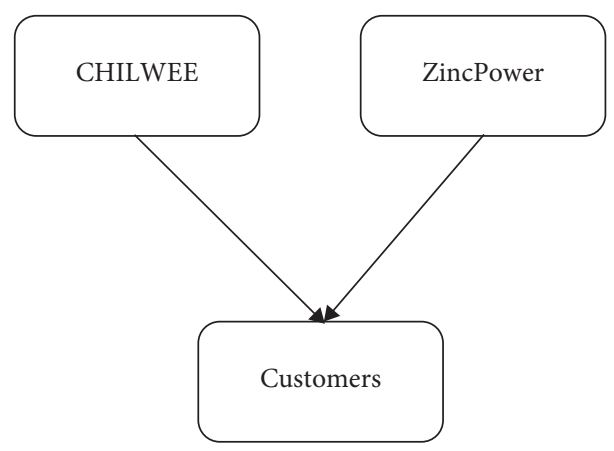

FIGURE 1: Supply chain analysis of zinc-nickel battery market.

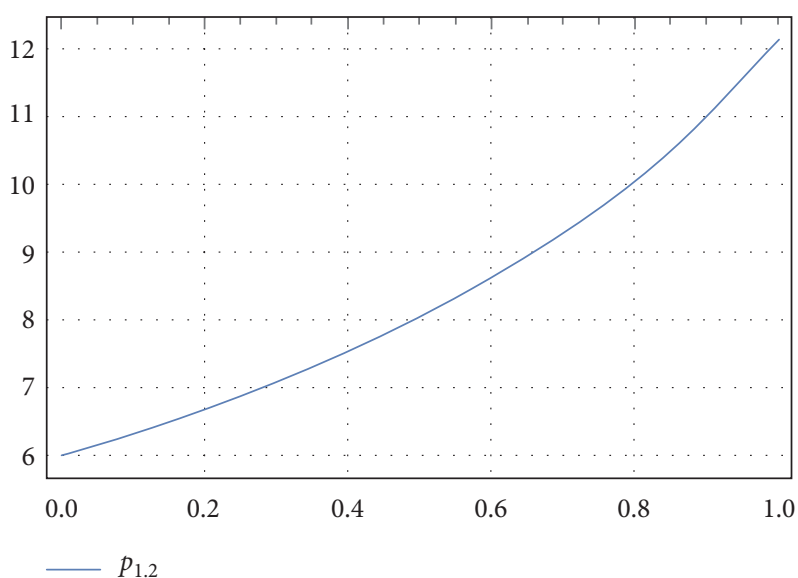

Figure 2: Product prices under $b$ changing.

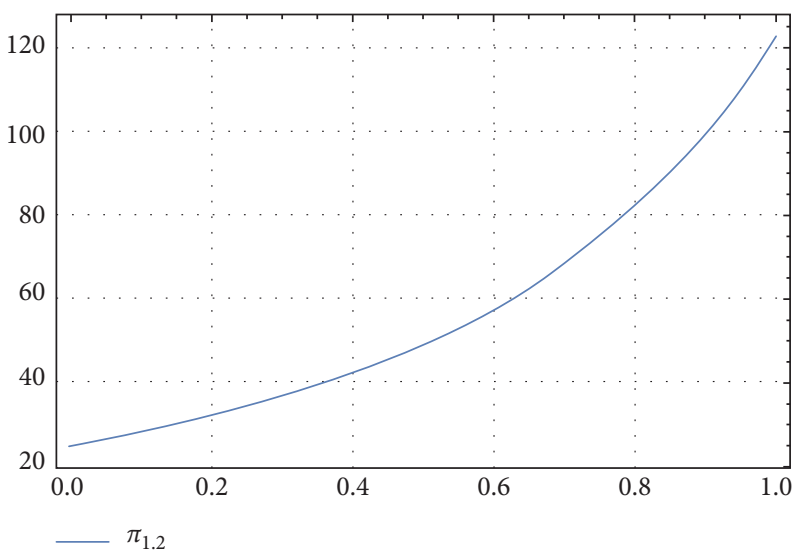

FIgURE 3: Corporate profits under $b$ changing.

increase. At the same time, both parties can jointly pursue high prices to achieve higher profits.

3.1.2. Three-Oligarch Game Analysis. Market environment is changing constantly, so the duopoly structure is easy to be broken. In terms of the zinc-nickel battery market, threeoligopoly competition market structure is the trend of times; we set up a three-oligarch competition model to research the competition of the three companies mentioned before.

$$
\begin{aligned}
& D_{1}=A-p_{1}+b p_{2}+k p_{3}+\varepsilon_{1}, \\
& D_{2}=A-p_{2}+b p_{1}+\mathrm{d} p_{3}+\varepsilon_{2}, \\
& D_{3}=A-p_{3}+k p_{1}+\mathrm{d} p_{2}+\varepsilon_{3} .
\end{aligned}
$$


In this model, $D_{1}, D_{2}$, and $D_{3}$, respectively, represent the market demand of the three enterprises, $A$ represents the total demand of the market, and $b, d$, and $k$ represent the market competition coefficient between each two enterprises. $\varepsilon_{1}, \varepsilon_{2}$, and $\varepsilon_{3}$ are the disturbance factors of demand of the three enterprises. Under these assumptions of demand, the profits of the three are shown as follows:

$$
\begin{aligned}
& \pi_{1}=\left(p_{1}-c_{1}\right)\left(A-p_{1}+b p_{2}+k p_{3}+\varepsilon_{1}\right), \\
& \pi_{2}=\left(p_{2}-c_{2}\right)\left(A-p_{2}+b p_{1}+\mathrm{d} p_{1}+\varepsilon_{2}\right), \\
& \pi_{3}=\left(p_{3}-c_{3}\right)\left(A-p_{3}+k p_{1}+\mathrm{d} p_{2}+\varepsilon_{3}\right) .
\end{aligned}
$$

In the case of the three oligarchs, we first consider the case where three enterprises have the same pricing power. In this case, there will be a Nash game between them. And the solution method is similar to before. The game results are as follows:

$$
\begin{aligned}
& p_{1}=\frac{(-2 b-\mathrm{d} k)\left(-2\left(a+c_{2}+\epsilon_{2}\right)-d\left(a+c_{3}+\epsilon_{3}\right)\right)+\left(4-d^{2}\right)\left(-2\left(a+c_{1}+\epsilon_{1}\right)-k\left(a+c_{3}+\epsilon_{3}\right)\right)}{16-4 b^{2}-4 d^{2}-4 b \mathrm{~d} k-4 k^{2}} \\
& p_{2}=-\frac{4 a+2 a b+2 a d+a b k+a d k-a k^{2}+2 b c_{1}+\mathrm{d} k c_{1}+4 c_{2}-k^{2} c_{2}+2 d c_{3}+b k c_{3}+2 b \epsilon_{1}+\mathrm{d} k \epsilon_{1}+4 \epsilon_{2}-k^{2} \epsilon_{2}+2 \mathrm{~d} \epsilon_{3}+b k \epsilon_{3}}{2\left(-4+b^{2}+d^{2}+b d k+k^{2}\right)} \\
& p_{3}=-\frac{4 a-a b^{2}+2 a d+a b d+2 a k+a b k+b d c_{1}+2 k c_{1}+2 d c_{2}+b k c_{2}+4 c_{3}-b^{2} c_{3}+b d \epsilon_{1}+2 k \epsilon_{1}+2 d \epsilon_{2}+b k \epsilon_{2}+4 \epsilon_{3}-b^{2} \epsilon_{3}}{2\left(-4+b^{2}+d^{2}+b \mathrm{~d} k+k^{2}\right)}
\end{aligned}
$$

The profits of the three enterprises are as follows:

$$
\begin{aligned}
& \pi_{1}=\frac{\left(4 a+2 a b+a b d-a d^{2}+2 a k+a d k+\left(-4+2 b^{2}+d^{2}+2 b d k+2 k^{2}\right) c_{1}+(2 b+\mathrm{d} k) c_{2}+b d c_{3}+2 k c_{3}+4 \epsilon_{1}-d^{2} \epsilon_{1}+2 b \epsilon_{2}+\mathrm{d} k \epsilon_{2}+b d \epsilon_{3}+2 k \epsilon_{3}\right)^{2}}{4\left(-4+b^{2}+d^{2}+b d k+k^{2}\right)^{2}}, \\
& \pi_{2}=\frac{\left(4 a+2 a b+2 a d+a b k+a d k-a k^{2}+(2 b+\mathrm{d} k) c_{1}+\left(-4+2 b^{2}+2 d^{2}+2 b d k+k^{2}\right) c_{2}+2 d c_{3}+b k c_{3}+2 b \epsilon_{1}+\mathrm{d} k \epsilon_{1}+4 \epsilon_{2}-k^{2} \epsilon_{2}+2 \mathrm{~d} \epsilon_{3}+b k \epsilon_{3}\right)^{2}}{4\left(-4+b^{2}+d^{2}+b d k+k^{2}\right)^{2}}, \\
& \pi_{3}=\frac{\left(4 a-a b^{2}+2 a d+a b d+2 a k+a b k+(b d+2 k) c_{1}+(2 d+b k) c_{2}-4 c_{3}+b^{2} c_{3}+2 d^{2} c_{3}+2 b d k c_{3}+2 k^{2} c_{3}+b d \epsilon_{1}+2 k \epsilon_{1}+2 d \epsilon_{2}+b k \epsilon_{2}+4 \epsilon_{3}-b^{2} \epsilon_{3}\right)^{2}}{4\left(-4+b^{2}+d^{2}+b d k+k^{2}\right)^{2}}
\end{aligned}
$$

To study the influence of product substitution rate on enterprise profits, we assign the parameter values other than substitution rate as follows: $\left\{a, c_{1}, c_{2}, c_{3}, \epsilon_{1}, \epsilon_{2}, \epsilon_{3}\right\}=\{10,1$, 1.5, 2, 1, 1.5, 2\} (Figures 4-6).

As is shown in the figures, the yellow area represents the profit of enterprise 1 , the blue one represents the profit of enterprise 2, and the green one represents the profit of enterprise 3. The figures above show the changes of enterprise profits with two other values after controlling the values of $d, k$, and $b$, respectively. $d, k$, and $b$ are the cross price elasticity coefficients of products produced by the three enterprises, which represent the mutual substitution rate of products.

It can be seen from the figures that when the substitution rate of two competing products of a certain company increases, its profits will increase substantially, and it will be ahead of the other two companies. This also reflects that when the product is facing a crisis, the company will be more conscious of survival and will continue to seek profits in order to survive. When a company has only one competing product replacement rate, its market leadership will play an important role.

3.2. Study on the Business Model of Renting and Selling Simultaneously. There are two sales modes in the market of zinc-nickel batteries: one is directly sale of products, and the other is renting products.

In this study, the supply chain structure is assumed as follows: for ZincPower, there are two sales channels of zincnickel batteries: one is traditional retail sales channel, and the other is renting and selling simultaneously. ZincPower and downstream retailers compose a Stackelberg game in which the upstream company ZincPower is the leader. We 


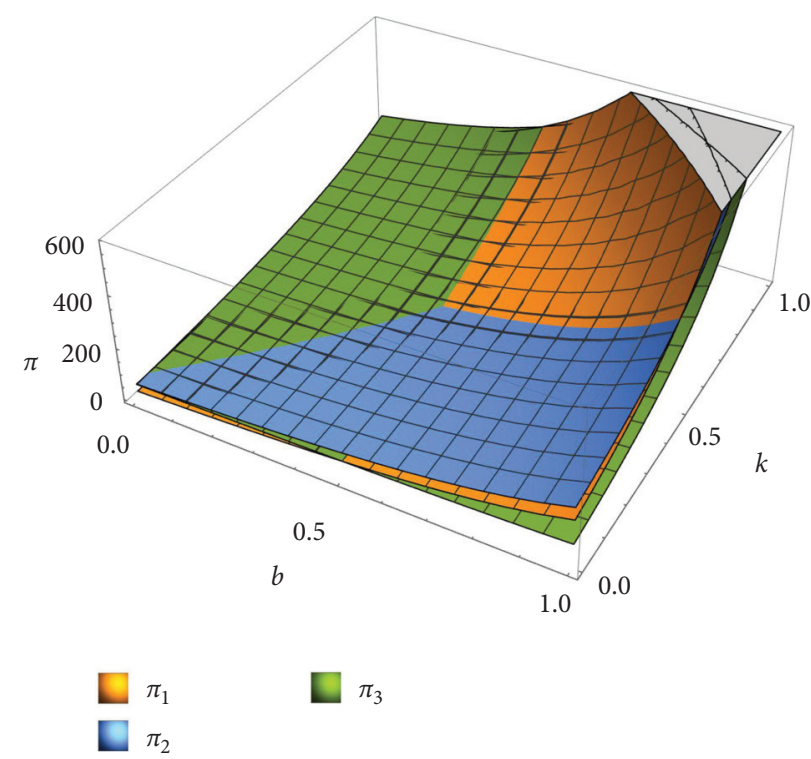

FIgURE 4: The influence of $b$ and $k$ on corporate profits when $d=0.5$.

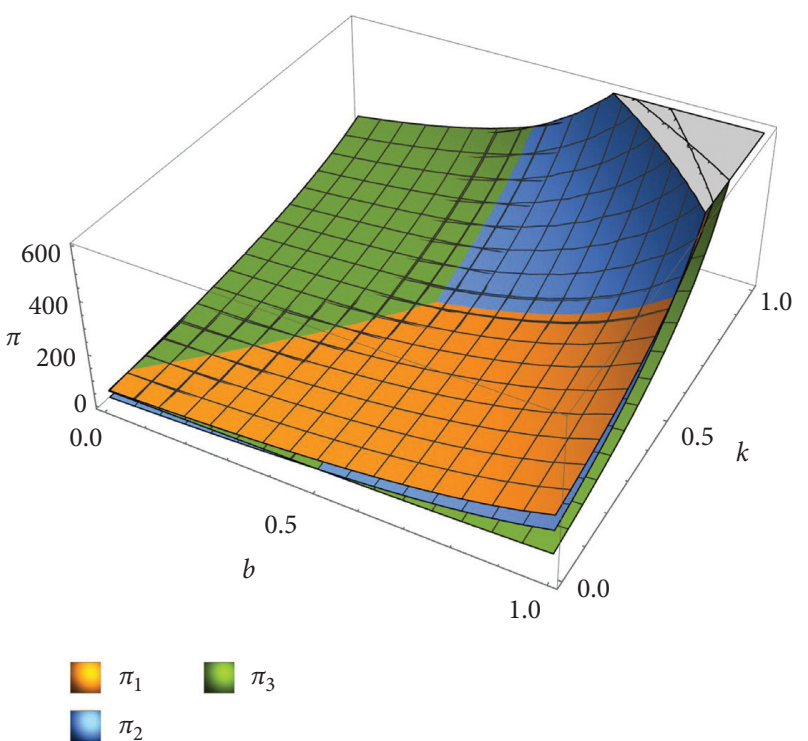

Figure 5: The influence of $b$ and $d$ on corporate profits when $k=0.5$.

also assume that the consumers strategically choose channels according to their own utility. The supply chain structure is shown in Figure 7.

To externalize the model, we suppose that ZincPower signs a wholesale price contract with the retailer at price $\omega$, and the retailer sells products to the consumer at $p^{R}$. At the same time, ZincPower rents and sells products directly by its own sales channel, in which the deposit is $V$, the rent of each period is $S$, and the market risk-free rate of return is $r$. The two parties play a two-stage game: after the upstream enterprise decides the rent $S$, the retailer decides the market price $p^{R}$.

Assuming that the market capacity is $f$, the psychological distance $x$ of consumers to the two channels is subject to uniform distribution $x \sim U[0, f]$. For specific consumers, $x=0$ means that consumers absolutely lean towards retailers, while $x=f$ means consumers absolutely lean towards the upstream enterprise. As the current rental and sales model is still relatively new, consumers still have the stickiness to traditional retail sales channel. Assuming that the coefficient of consumers' preference for the retail channel is $\alpha(\alpha<1)$ and that the term of use includes a cycle of $n$ rent payment, the utility of consumers to purchase from the two channels is shown as

$$
\left\{\begin{array}{l}
U_{R}=U_{0}-p^{R}-\alpha x, \\
U_{M}=U_{0}-V-\frac{r S}{1-r}\left(1-r^{n}\right)-(f-x) .
\end{array}\right.
$$




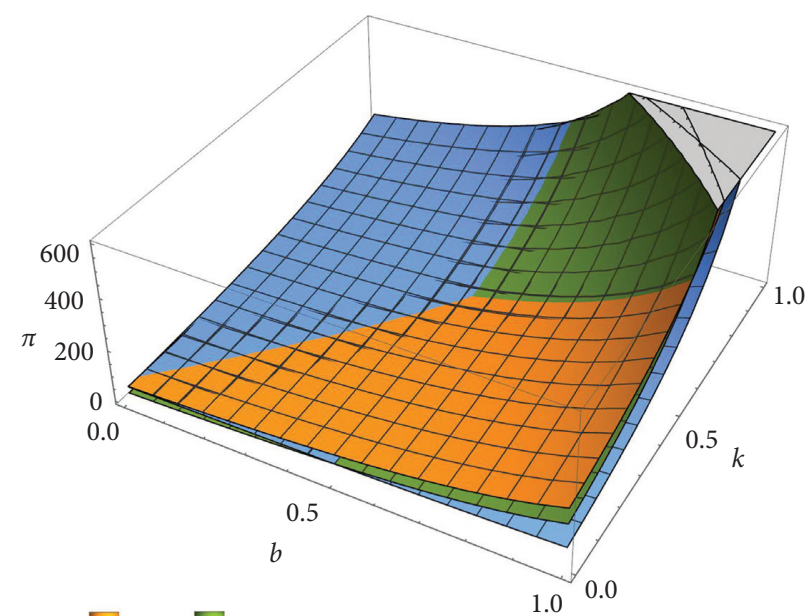

FIGURE 6: The influence of $k$ and $d$ on corporate profits when $b=0.5$.

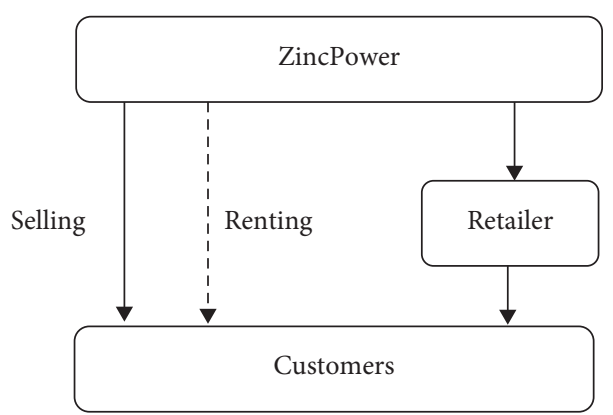

Figure 7: The supply chain structure.

Consumers at the psychological distance $x=(1 / 1+\alpha)\left(f+V+(r S / 1-r)\left(1-r^{n}\right)-p^{R}\right)$ have the same preferences for both channels. Therefore, the market demand of the two channels can be expressed as

$$
\left\{\begin{array}{l}
D_{R}=\frac{1}{1+\alpha}\left(f+V+\frac{r S}{1-r}\left(1-r^{n}\right)-p^{R}\right), \\
D_{M}=f-\frac{1}{1+\alpha}\left(f+V+\frac{r S}{1-r}\left(1-r^{n}\right)-p^{R}\right) .
\end{array}\right.
$$

$$
\left\{\begin{array}{l}
\pi_{R}=\frac{1}{1+\alpha}\left(f+V+\frac{r S}{1-r}\left(1-r^{n}\right)-p^{R}\right)\left(p^{R}-\omega\right) \\
\pi_{M}=\frac{1}{1+\alpha}\left(f+V+\frac{r S}{1-r}\left(1-r^{n}\right)-p^{R}\right)(\omega-c) \\
+\left(V+\frac{r S}{1-r}\left(1-r^{n}\right)\right)\left(f-\frac{1}{1+\alpha}\left(f+V+\frac{r S}{1-r}\left(1-r^{n}\right)-p^{R}\right)\right)
\end{array}\right.
$$

3.2.1. Solution of the Model. In reality, upstream enterprises usually make decisions first; then, retailers decide the market prices according to their decisions. Therefore, the best
Profits of the enterprise and the retailer can be written as follows: 


$$
\begin{aligned}
\frac{\delta \pi_{R}}{\delta p_{R}} & =\frac{(1-r)(v+\omega)+r\left(1-r^{n}\right) s-(1-r)\left(2 p_{R}-f\right)}{(1-r)(1+\alpha)}, \\
p_{R} & =f+v+w+\frac{r s\left(1-r^{n}\right)}{1-r} .
\end{aligned}
$$

Substituting $p_{R}=f+v+w+\left(r s\left(1-r^{n}\right) / 1-r\right)$ into $\pi_{M}$, we can get the optimal solution as follows:

$$
\begin{aligned}
& \left\{\begin{array}{l}
s^{*}=\frac{(1-r)(f-c+2 w-2 v+2 f \alpha)}{2 r\left(1-r^{n}\right)}, \\
p_{r}^{*}=\frac{1}{4}(4 w-c+f(3+2 \alpha)),
\end{array}\right. \\
& \left\{\begin{array}{l}
\pi_{m}=\frac{(f+2 \alpha f)^{2}+c^{2}-2 c f(3+2 \alpha)}{8(1+\alpha)}+f w, \\
\pi_{r}=\frac{(c-f(3+2 \alpha))^{2}}{16(1+\alpha)} .
\end{array}\right.
\end{aligned}
$$

3.2.2. Numerical Simulation. We assign $\alpha=0.8, f=100$, $c=50, w=100, n=3, v=100, r=0.05$ and draw the changes of profits as follows.

From Figure 8, we can see that as consumers' preference for retail channel $\alpha$ increases, the profits of both channels have increased. But the deposit $v$ has a smaller impact on the two profits. This shows that the purchase of products from the retail channel will drive the profits of the two channels, among which the profit growth of the retail channel will be greater than that of the manufacturer channel.

From Figure 9, we can see that with the increase in preference distribution, the profits of both channels have increased significantly. This shows that the growth of consumer consumption will have the basic profit to expand the entire market. At the same time, we can also see that when the preference distribution reaches a certain level and the wholesale price is less than a certain value, the profit of the retail channel will exceed that of the manufacturer channel.

Comparing Figure 9 with Figure 10, we can more clearly see the optimal profit range of the two channels under the change of $f$ and $\omega$. This can help decision makers make corresponding strategies faster and control product launches in channels based on market conditions.

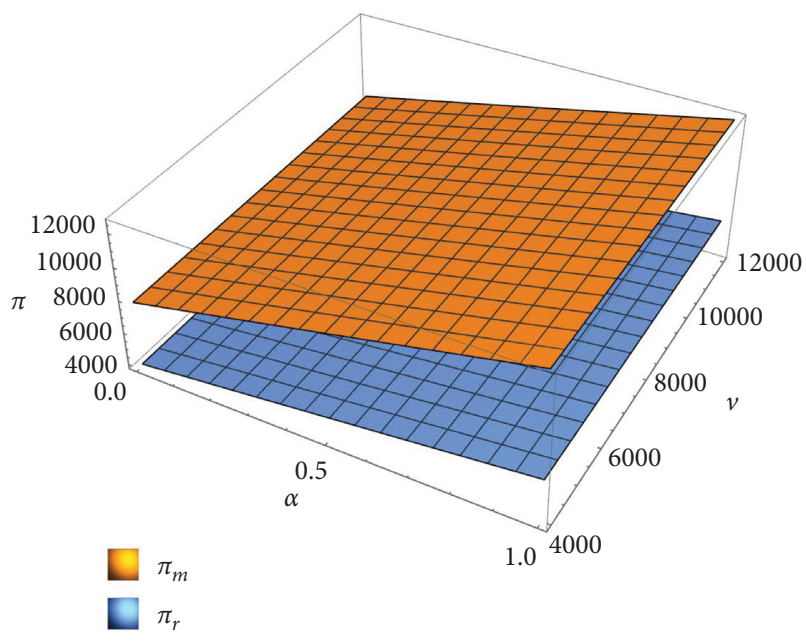

FIGURE 8: The changes in profits with $v$ and $\alpha$.

\section{Cost Study of the Zinc-Nickel Battery}

The revenue of a battery manufacturer is greatly affected by the production cost. As a metal-based battery industry, the profit of ZincPower is greatly influenced by the price of zinc and nickel. Therefore, it is of great significance to pay close attention to the spot and futures prices of zinc and nickel.

4.1. Study of Spot Prices and Future Prices of Zinc and Nickel. Zinc and nickel are the main raw materials of zinc-nickel batteries whose prices greatly affect the production cost. The fluctuation of the prices of zinc and nickel at the Shanghai Stock Exchange are shown in Figure 11 and Figure 12.

4.2. Impact of Spot Prices of Zinc and Nickel on the Profits of ZincPower. In the first chapter, we have studied the profits of supplier in the duopoly and triple oligopoly cases. In this supply chain model, the effect of production cost on profit cannot be ignored. In the following chapter, we will study the impact of spot prices of zinc and nickel on corporate profits.

Assume that the production cost of zinc-nickel battery of enterprise $i$ is $c_{i}=c_{t_{i}}+c_{\mathrm{Zn}}+c_{\mathrm{Ni}}$, in which $c_{t_{i}}$ denotes costs other than raw materials, $c_{\mathrm{Zn}}$ is the spot price of zinc, and $c_{\mathrm{Ni}}$ is the spot price of nickel. Then, in the three-oligopoly market, the price of products is

$$
p_{1}=\frac{(-2 b-\mathrm{d} k)\left(-2\left(a+c_{2}+\epsilon_{2}\right)-d\left(a+c_{3}+\epsilon_{3}\right)\right)+\left(4-d^{2}\right)\left(-2\left(a+c_{1}+\epsilon_{1}\right)-k\left(a+c_{3}+\epsilon_{3}\right)\right)}{16-4 b^{2}-4 d^{2}-4 b d k-4 k^{2}} .
$$

The profit is 


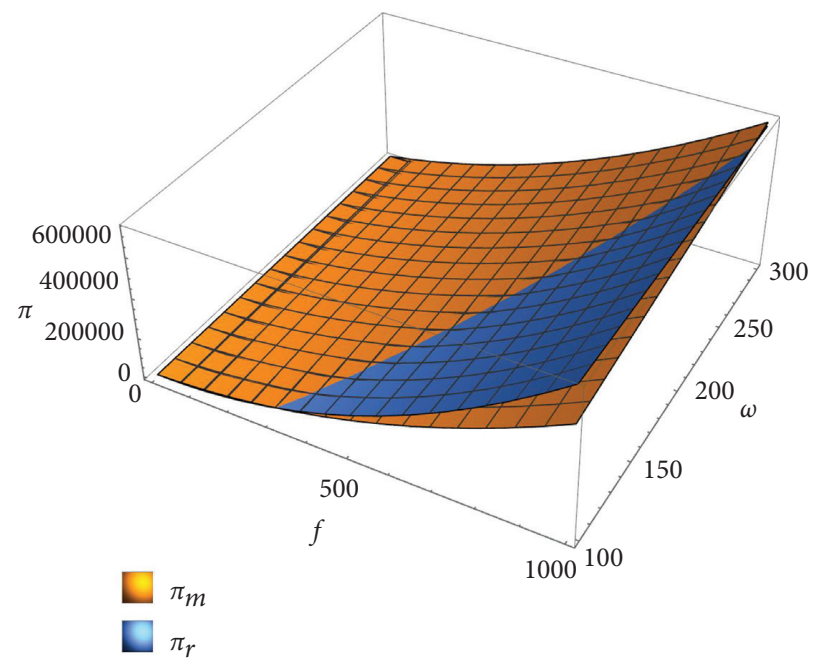

Figure 9: The changes of profits with $f$ and $\omega$.

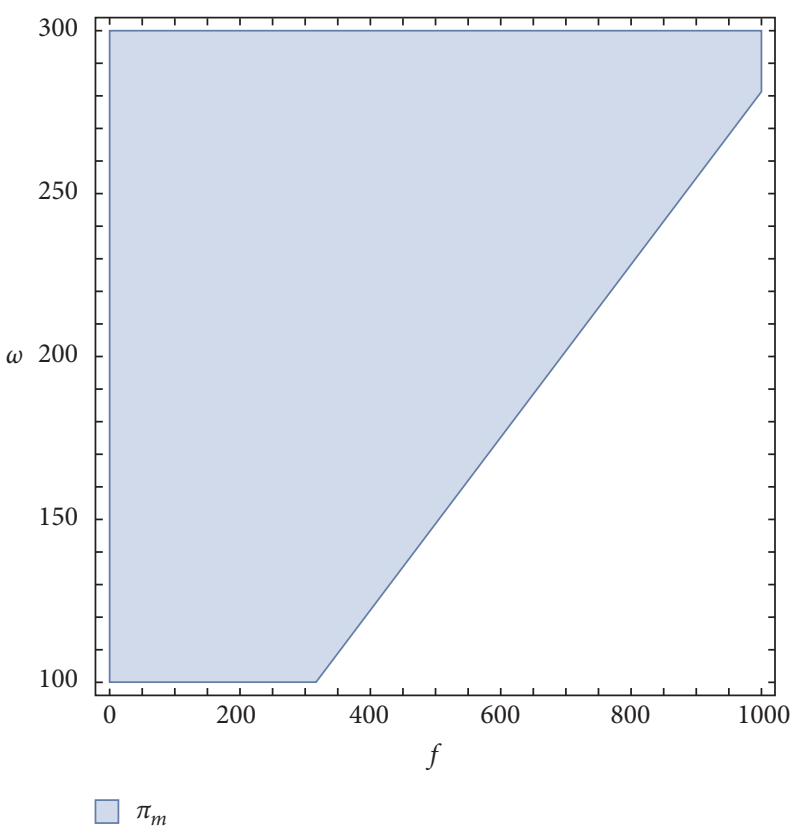

Figure 10: The interval of $f$ and $\omega$ where the manufacturer can make better profits.

$\pi_{1}=\frac{\left(4 a+2 a b+a b d-a d^{2}+2 a k+a d k+\left(-4+2 b^{2}+d^{2}+2 b d k+2 k^{2}\right) c_{1}+(2 b+\mathrm{d} k) c_{2}+b d c_{3}+2 k c_{3}+4 \epsilon_{1}-d^{2} \epsilon_{1}+2 b \epsilon_{2}+d k \epsilon_{2}+b d \epsilon_{3}+2 k \epsilon_{3}\right)^{2}}{4\left(-4+b^{2}+d^{2}+b d k+k^{2}\right)^{2}}$.

When $a=10, b=0.3, d=0.4, k=0.5, \varepsilon_{1}=\varepsilon_{2}=\varepsilon_{3}=3$, $c_{t 1}=1, c_{t 2}=1.5$, and $c_{t 3}=1.8$, we can get

$$
\begin{aligned}
& p_{1}=11.91+0.84 c_{n}+0.84 c_{z}, \\
& \pi_{1}=19.01-3.55 c_{n}+0.02 c_{n}^{2}-3.55 c_{z}+0.05 c_{n} c_{z}+0.03 c_{z}^{2} .
\end{aligned}
$$

The profit changes with the spot prices of zinc and nickel can be shown in Figure 13.

From Figure 13, we can see that when the spot price of zinc and nickel decreases, the profit of the entire company will increase significantly. This is also in line with reality. Because when the spot price of zinc and nickel decreases, the 


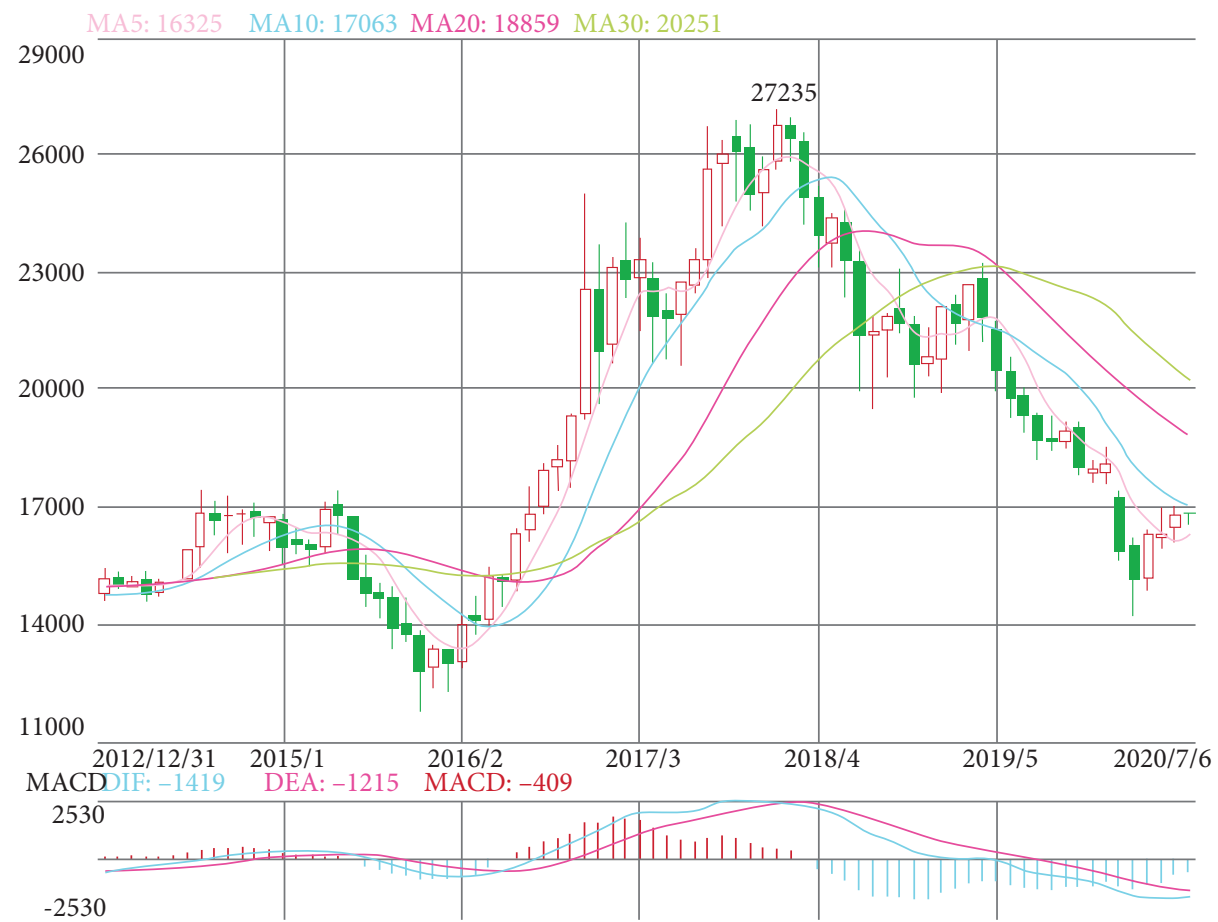

(a)

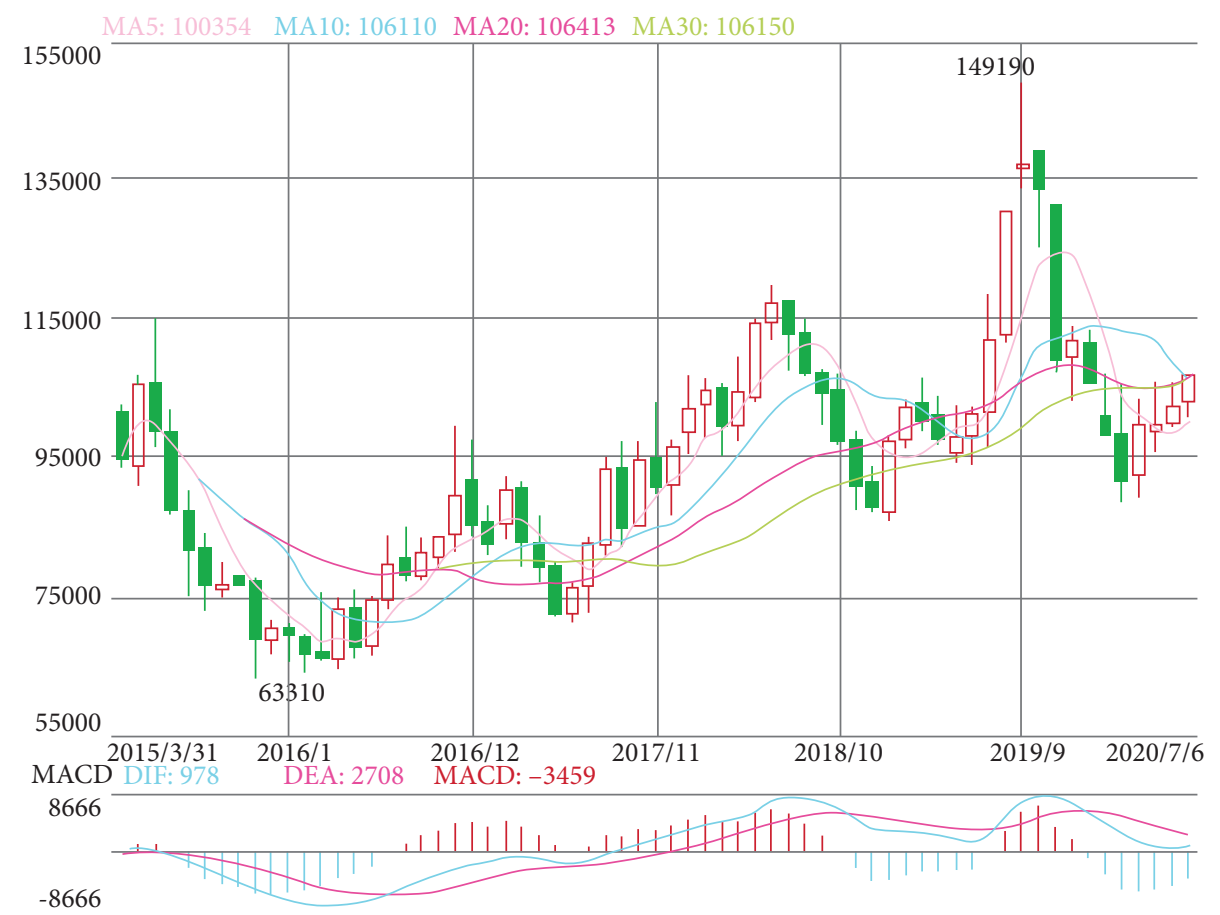

(b)

Figure 11: The fluctuation of main future prices of zinc and nickel at the Shanghai stock exchange. (a) Zinc. (b) Nickel.

company's procurement costs will be reduced, and there will be more profit margins.

\section{Development Research of ZincPower}

For long-term development, the enterprise must meet the following conditions: (1) Favorable geographical location: the geographical location determines the logistics efficiency and main market area of one enterprise, and a good geographical location can greatly reduce logistics costs while provides a broad market. (2) Reasonable ownership structure: the ownership structure is the foundation of corporate governance structure, and corporate governance structure is the specific operation form of the ownership structure. Different 


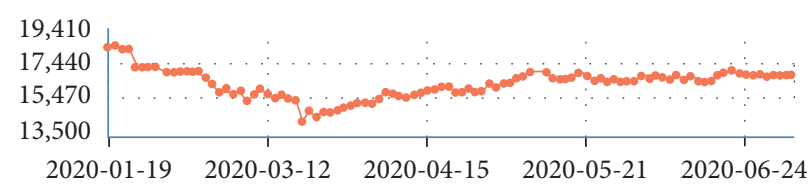

(a)

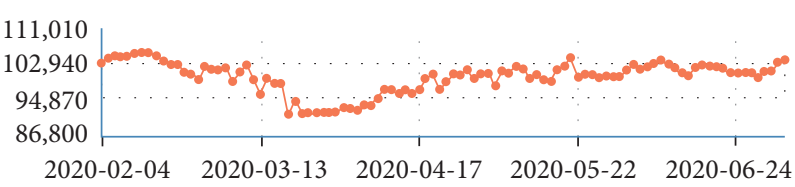

(b)

Figure 12: The fluctuation of main spot price of zinc and nickel at the Shanghai stock exchange. (a) Zinc. (b) Nickel.

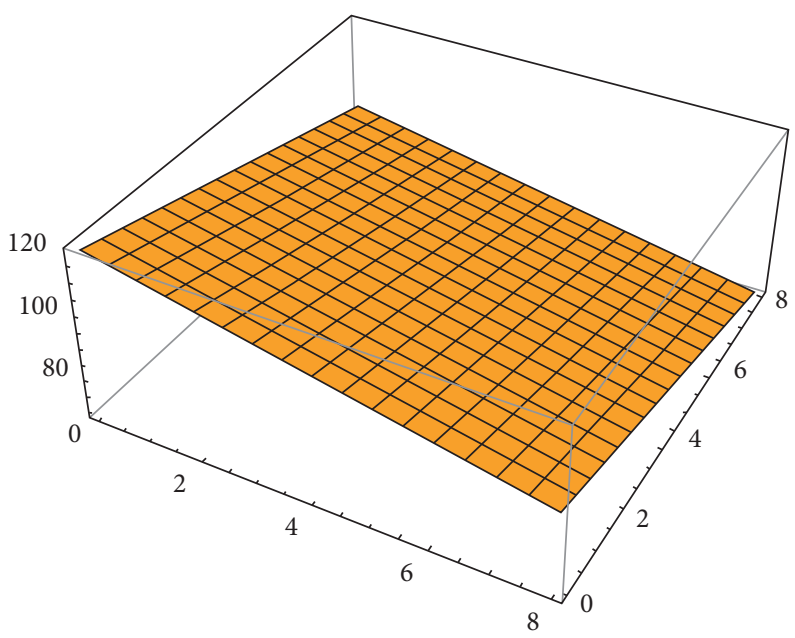

Figure 13: The profit changes with the spot prices of zinc and nickel.

ownership structures determine different organizational structures of enterprises, thus determining different corporate governance structures and ultimately determining the behavior and performance of one enterprise. (3) Government policies: the production of enterprises is closely related to government policies. For battery companies, closely understand the government's policies on environmental protection, as well as the policies for small- and medium-sized enterprises will be conductive to better development. (4) Financing mode: for further and sound progress, choosing an appropriate financing mode is of great significance for any company.

5.1. The Geographical Layout. The geographical layout is important for an enterprise that is trying to be the strongest brand in this industry. As shown in Figure 14, Tianjin is a city with a developed chemical industry which has great convenience in providing the upstream raw materials for battery production. Relying on the advantages of raw materials, ZincPower can reduce production costs and thus increase profits. As one of the eight pillar industries in Tianjin, the new energy and new materials industry has a large market and a great room for future growth. Located in north China, Tianjin Port also provides a broad market as well as great convenience of exporting for ZincPower.

As a central city in south Shandong Province, Zaozhuang also has some advantages. By 2018, there are five districts and one county-level city under Zaozhuang's jurisdiction, covering an area of 4,563 square kilometers, with permanent resident $3.927,300$ and urbanization rate of $58.88 \%$. The seven high-tech industrial parks in Zaozhuang can provide supporting facilities for product production.

5.2. Study of Equity Structure and Government Policy. Ownership structure is the foundation of corporate governance structure, and corporate governance structure is the specific operation form of ownership structure. Different ownership structures determine different organizational structures of enterprises, different corporate governance structures, and ultimately affect the performance of enterprises. So, it is also of great significance for enterprises to clarify the shareholding structure.

ZincPower has set up a production park in Zaozhuang, Shandong Province. For the first three years, the enterprise can use the factory for free. And then the factory rental is paid after the enterprise makes a profit. At the same time, the government will introduce upstream and downstream supporting suppliers to the company to facilitate the production of enterprises. The policy of paying no rent in the early stage of production can also relieve the financial pressure of the enterprise, making it possible for the enterprise to focus on the establishment of product lines and the research and development of products.

5.3. Effect of Combination of Bank Loan and Insurance on Corporate Financing. Small- and medium-sized technical enterprises play an important role in domestic economy, but have difficulty financing for a long time due to the limited financing channels. In order to reduce the financing cost of 


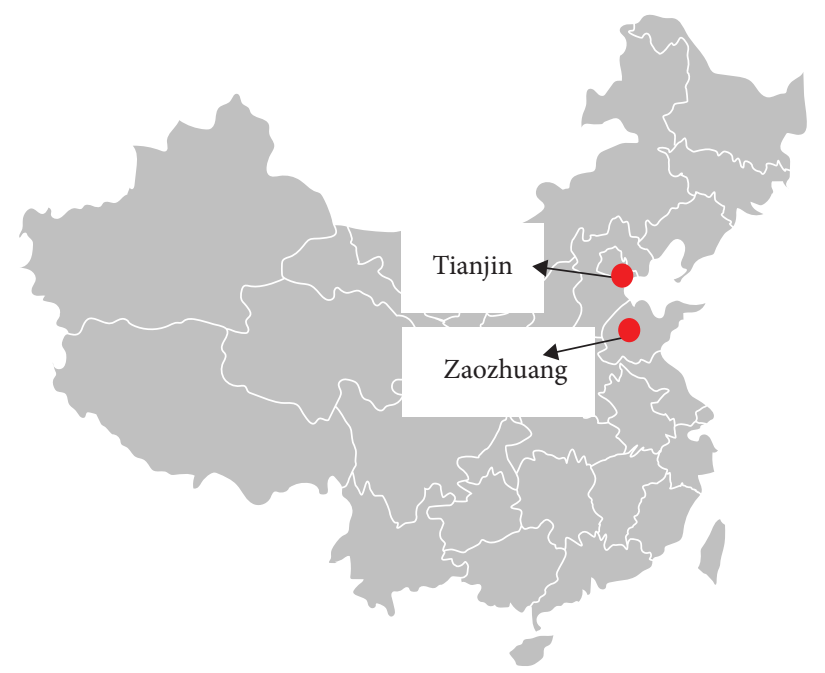

Figure 14: The geographical layout of ZincPower.

small- and medium-sized technology-based enterprises and spread the financial risks, small-loan guarantee insurance has been carried out all over the country. Considering the features of small- and medium-sized technical enterprises such as asset-light, lack of guarantee, and no mortgage, this insurance introduces insurance tools to spread loan risks, while the government invest in risk compensation reserve funds. The framework of bank loans and insurance for corporate financing is shown in Figure 15.

The advantages of small-loan insurance are mainly reflected in following aspects: (1) Insurance companies have strong risk diversification ability. The small-loan insurance is one kind of insurance, aiming at spreading risk through actuarial principle and reinsurance arrangement. Unlike guarantee companies, the business scope of insurance companies may be distributed across the country or even over the world. Therefore, they can spread the risks in a wider range and enjoy high credit ratings. At the same time, the loan risks tend to be regional; that is, the repayment ability of enterprises is affected by the level of local economic development and local policies. Due to the small scale and relatively concentrated business, guarantee companies tend to bear relatively high correlation risks and large operational fluctuations. (2) Insurance companies have the advantages of professional risk management. Insurance companies, especially property insurance companies, have a broad insurance product system, covering the scope of enterprise property, third-party liability, employee accidents, etc., have a deep understanding of the risk status and other basic conditions of insurance companies, and have a good customer base. Modern insurance companies pay more attention to enterprise risk management and can design a package of risk management programs for enterprises even before any actual loss, so as to help enterprises realize corporate goals on the basis of dispersing and transferring operational risks. (3) Insurance companies have lower coordination costs. Generally, the third-party bank also engages in a small-loan insurance program. From the perspective of small-loan insurance, the bank is the insured, whose interests are protected by small-loan insurance, but the bank cannot make loans at will and earn interest to let the insurance company bear the risk of default because it is insured by the insurance company. Under the general trend of mixed operation, insurance companies and banks are increasingly closely linked in business cooperation and equity penetration. In most cases, banks work with institutions that provide guarantees and share the risks. Through small-loan insurance, the government can leverage the two financial levers of insurance and banks to realize the effective allocation of resources.

5.4. Industry Analysis of Zinc-Nickel Battery under the COVID-19 Pandemic. The COVID-19 pandemic outbroken in 2020 has affected many industries; it is of practical significance to study the impact of the pandemic on the sales of zinc-nickel batteries. In the early stage of the pandemic, strict controls were put in place, and industries were largely shut down for the first few months in 2020. The domestic economy was affected to a certain extent, and the national GDP also showed negative growth, falling by $6.8 \%$. With the gradual control of the pandemic in China, the state's control policies on population movement have been gradually relaxed, and the support for enterprises to resume production has been helpful. The domestic economy has been alleviated. According to the indicators in March, the manufacturing index, import and export, household consumption, and other data have been significantly improved compared with the previous two months. It is generally believed that China's economy is expected to continue to pick up and improve in the next stage, with the overall economic growth presenting a "V" shape. It is worth noting that the pandemic abroad has not been effectively controlled. The COVID-19 pandemic has become a major problem faced by human society. Under the conditions of the pandemic, the world economy will continue to decline in a comprehensive manner. In 2021, the world economy is still struggling to move forward under the heavy drag of COVID-19. A full recovery of the global 


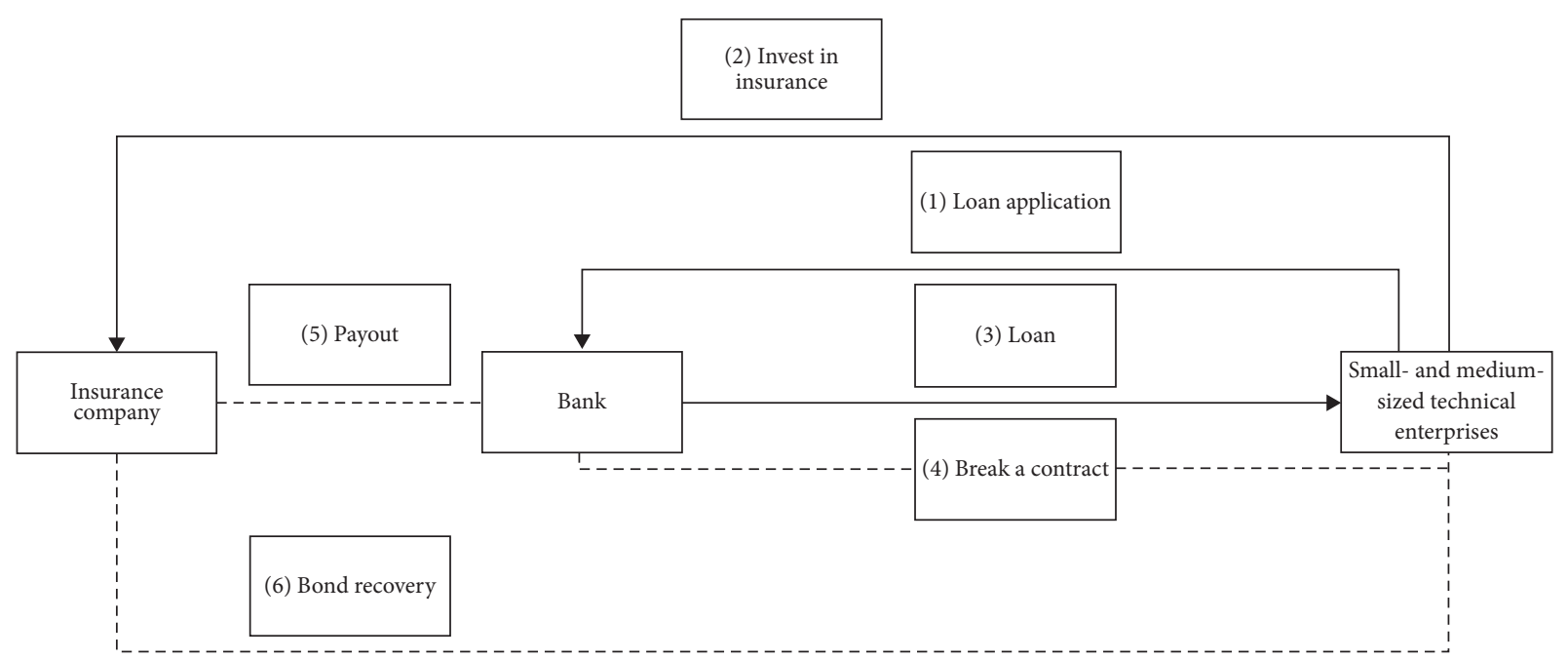

FIgURE 15: The framework of bank loans and insurance for corporate financing.

economy within this year seems to be impossible according to the forecasts of various authoritative international research institutions.

Considering the COVID-19 pandemic globally, it is a favorable opportunity for China, where the pandemic is well under control, and the slow or even stagnant development of the global industry also provides a chance for export of domestic products. In 2019, the zinc-nickel batteries produced by CHILWEE were displayed in Europe, which attracted wide attention from European and American customers. The zinc-nickel batteries exported by China have strong competitiveness in foreign countries, and their export advantages are even more significant in current stagnation period of foreign industry. Due to the impact of the pandemic, the prices of zinc and nickel and the main raw materials for zinc-nickel batteries fluctuated greatly. In the early stage of the pandemic, the spot prices of zinc and nickel continued to fall. With the further control of the pandemic, the prices of zinc and nickel stabilized and were lower than the average price in 2019. The reduction of raw material cost is of great help to the development of zinc-nickel battery industry.

\section{Data Availability}

The data used to support the findings of this study are available from the corresponding author upon request. The questionnaire data were acquired mainly through e-mail and paper filling out.

\section{Conflicts of Interest}

The authors declare that they have no conflicts of interest regarding the publication of this paper.

\section{References}

[1] C. G. Korpeoglu, E. Körpeoğlu, and S.-H. Cho, "Supply chain competition: a market game approach," Management Science, vol. 66, no. 12, pp. 5648-5664, 2020.
[2] Q. Feng, G. Lai, and L. X. Lu, "Dynamic bargaining in a supply chain with asymmetric demand information," Management Science, vol. 61, no. 2, pp. 301-315, 2015.

[3] R. Beer, H.-S. Ahn, and S. Leider, "Can trustworthiness in a supply chain be signaled?” Management Science, vol. 64, no. 9, pp. 3974-3994, 2018.

[4] W. Shang, A. Y. Ha, and S. Tong, "Information sharing in a supply chain with a common retailer," Management Science, vol. 62, no. 1, pp. 245-263, 2016.

[5] A. Hafezalkotob, A. Alavi, and A. Makui, "Government financial intervention in green and regular supply chains: multi-level game theory approach," International Journal of Management Science and Engineering Management, vol. 11, no. 3, pp. 167-177, 2016.

[6] E. Ang, D. A. Iancu, and R. Swinney, "Disruption risk and optimal sourcing in multitier supply networks," Management Science, vol. 63, no. 8, pp. 2397-2419, 2017.

[7] D. Gao, X. Zhao, and W. Geng, "A delay-in-payment contract for Pareto improvement of a supply chain with stochastic demand," Omega, vol. 49, no. 12, pp. 60-68, 2014.

[8] B. C. Giri and T. Maiti, "Supply chain model with price- and trade credit-sensitive demand under two-level permissible delay in payments," International Journal of Systems Science, vol. 44, no. 5, p. 12, 2013.

[9] I. Mallidis, R. Dekker, and D. Vlachos, "The impact of greening on supply chain design and cost: a case for a developing region," Journal of Transport Geography, vol. 22, no. 2, pp. 118-128, 2012.

[10] S. Benjaafar, Y. Li, and M. Daskin, "Carbon footprint and the management of supply chains: insights from simple models," IEEE Transactions on Automation Science and Engineering, vol. 10, no. 1, pp. 99-116, 2013.

[11] T. Paksoy, E. Özceylan, and G. W. Weber, "A multi objective model for optimization of a green supply chain network," Global Journal of Technology \& Optimization, vol. 1239, no. 1, pp. 311-320, 2011.

[12] C. Dellarocas, "Double marginalization in performance-based advertising: implications and solutions," Management Science, vol. 58, no. 6, pp. 1178-1195, 2012.

[13] G. P. Cachon, "Supply chain coordination with contracts," Handbooks in Operations Research and Management Science, vol. 11, pp. 227-339, 2013. 
[14] M. A. Lariviere, "OM forum-supply chain contracting: doughnuts to bubbles," Manufacturing \& Service Operations Management, vol. 18, no. 3, pp. 309-313, 2016.

[15] A. Y. Ha and S. Tong, "Contracting and information sharing under supply chain competition," Management Science, vol. 54, no. 4, pp. 701-715, 2018.

[16] T. Pfeiffer, "A comparison of simple two-part supply chain contracts," International Journal of Production Economics, vol. 180, pp. 114-124, 2016.

[17] A. Hafezalkotob, "Competition of two green and regular supply chains under environmental protection and revenue seeking policies of government," Computers \& Industrial Engineering, vol. 82, pp. 103-114, 2015.

[18] Y. Tian, K. Govindan, and Q. Zhu, "A system dynamics model based on evolutionary game theory for green supply chain management diffusion among Chinese manufacturers," Journal of Cleaner Production, vol. 80, no. 7, pp. 96-105, 2014.

[19] C.-T. Zhang, H.-X. Wang, and M.-L. Ren, "Research on pricing and coordination strategy of green supply chain under hybrid production mode," Computers \& Industrial Engineering, vol. 72, no. 11, pp. 24-31, 2014.

[20] B. R. Sarker, A. M. M. Jamal, and S. Wang, "Supply chain models for perishable products under inflation and permissible delay in payment," Computers \& Operations Research, vol. 27, no. 1, pp. 59-75, 2000.

[21] M.-S. Chern, Y.-L. Chan, J.-T. Teng, and S. K. Goyal, "Nash equilibrium solution in a vendor-buyer supply chain model with permissible delay in payments," Computers \& Industrial Engineering, vol. 70, no. 1, pp. 116-123, 2014.

[22] L. Waltman, N. J. van Eck, R. Dekker, and U. Kaymak, “An evolutionary model of price competition among spatially distributed firms," Computational Economics, vol. 42, no. 4, pp. 373-391, 2013.

[23] M. T. Yassen and H. N. Elsadany, "Analysis of a duopoly game with delayed bounded rationality," Applied Mathematics and Computation, vol. 138, no. 2, pp. 387-402, 2003.

[24] J. Ma and F. Si, "Complex dynamics of a continuous Bertrand duopoly game model with two-stage delay," Entropy, vol. 18, no. 7, p. 266, 2016.

[25] A. A. Elsadany, H. N. Agiza, and E. M. Elabbasy, "Complex dynamics and chaos control of heterogeneous quadropoly game," Applied Mathematics and Computation, vol. 219, no. 24, pp. 11110-11118, 2013.

[26] L. Shi, Z. Sheng, and F. Xu, "Complexity analysis of remanufacturing duopoly game with different competition strategies and heterogeneous players," Nonlinear Dynamics, vol. 82, no. 3, pp. 1081-1092, 2015.

[27] F. Tramontana and A. E. A. Elsadany, "Heterogeneous triopoly game with isoelastic demand function," Nonlinear Dynamics, vol. 68, no. 1, pp. 187-193, 2012.

[28] T. Li and J. Ma, "Complexity analysis of the dual-channel supply chain model with delay decision," Nonlinear Dynamics, vol. 78, no. 4, pp. 2617-2626, 2014.

[29] L. Xie, P. Hou, and H. Han, "Implications of government subsidy on the vaccine product $\mathrm{R} \& \mathrm{D}$ when the buyer is risk averse," Transportation Research Part E: Logistics and Transportation Review, vol. 146, Article ID 102220, 2021.

[30] W. Lou and J. Ma, "Complexity of sales effort and carbon emission reduction effort in a two-parallel household appliance supply chain model," Applied Mathematical Modelling, vol. 64, pp. 398-425, 2018.

[31] L. Xie, J. Ma, and H. Han, "Implications of stochastic demand and manufacturers' operational mode on retailer's mixed bundling strategy and its complexity analysis," Applied Mathematical Modelling, vol. 55, pp. 484-501, 2018.

[32] T. Puu, "The chaotic duopolists revisited," Journal of Economic Behavior and Organization, vol. 33, no. 3-4, pp. 385394, 1998.

[33] Z. Zhang and W. Yu, "Complexity of the Hotelling model with bounded rationality rules," Systems Engineering - Theory \& Practice, vol. 35, no. 4, pp. 920-927, 2015.

[34] Q. Gao and J. H. Ma, "Chaos and Hopf bifurcation of a finance system," Nonlinear Dynamics, vol. 58, no. 1, pp. 209-216, 2009.

[35] J. Ma and W. Ren, "Complexity and Hopf bifurcation analysis on a kind of fractional-order IS-lm macroeconomic system," International Journal of Bifurcation and Chaos, vol. 26, no. 11, Article ID 1650181, 2016.

[36] J. Ma and L. Xie, "The comparison and complex analysis on dual-channel supply chain under different channel power structures and uncertain demand," Nonlinear Dynamics, vol. 83, no. 3, pp. 1379-1393, 2016.

[37] J. H. Ma and R. Hao, "Influence of government regulation on the stability of dual-channel recycling model based on customer expectation," Nonlinear Dynamics, vol. 94, no. 1, pp. 1775-1790, 2018.

[38] J. Ma, Y. Hou, Z. Wang, and W. Yang, "Pricing strategy and coordination of automobile manufacturers based on government intervention and carbon emission reduction," Energy Policy, vol. 148, Article ID 111919, 2021.

[39] J. Ma, Y. Hou, W. Yang, and Y. Tian, "A time-based pricing game in a competitive vehicle market regarding the intervention of carbon emission reduction," Energy Policy, vol. 142, no. 6, Article ID 111440, 2020.

[40] J. Ma and L. Sun, "Complexity analysis about nonlinear mixed oligopolies game based on production cooperation," IEEE Transactions on Control Systems Technology, vol. 26, no. 4, pp. 1532-1539, 2018.

[41] K. Pyragas, "Continuous control of chaos by self-controlling feedback," Physics Letters A, vol. 170, pp. 421-428, 1992.

[42] L. Xie, J. H. Ma, and M. Goh, "Supply chain coordination in the presence of uncertain yield and demand," International Journal of Production Research, vol. 20, no. 5, pp. 1-17, 2020.

[43] S. Nasser and D. Turcic, "To commit or not to commit: revisiting quantity vs. Price competition in a differentiated industry," Management Science, vol. 62, no. 6, pp. 1719-1733, 2016.

[44] F. Wu and J. Ma, "Evolution dynamics of agricultural internet of things technology promotion and adoption in China," Discrete Dynamics in Nature and Society, vol. 2020, Article ID 1854193, 18 pages, 2020.

[45] T. Xu and J. Ma, "Feed-in tariff or tax-rebate regulation? Dynamic decision model for the solar photovoltaic supply chain," Applied Mathematical Modelling, vol. 89, no. 2, pp. 1106-1123, 2021.

[46] B. Bao, J. Ma, and M. Goh, "Short- and long-term repeated game behaviours of two parallel supply chains based on government subsidy in the vehicle market," International Journal of Production Research, vol. 58, no. 24, pp. 7507-7530, 2020.

[47] K. Zhang and M. Sarvary, "Differentiation with user-generated content," Management Science, vol. 61, no. 4, pp. 898-914, 2015. 